\title{
Sequential Postsynaptic Maturation Governs the Temporal Order of GABAergic and Glutamatergic Synaptogenesis in Rat Embryonic Cultures
}

\author{
Lunbin Deng, ${ }^{1,2 *}$ Jun Yao, ${ }^{1,2 \star}$ Cheng Fang, ${ }^{1,2,3}$ Ning Dong, ${ }^{1,2}$ Bernhard Luscher, ${ }^{1,2,3,4}$ and Gong Chen ${ }^{1,2}$ \\ ${ }^{1}$ Department of Biology, ${ }^{2}$ The Huck Institutes of Life Sciences, ${ }^{3}$ Department of Biochemistry and Molecular Biology, and ${ }^{4}$ Department of Psychiatry, \\ Pennsylvania State University, University Park, Pennsylvania 16802
}

\begin{abstract}
Sequential formation of GABAergic and glutamatergic synapses is thought to be crucial for constructing the stereotypic neural networks during brain development. However, why GABAergic synapses are formed earlier than glutamatergic synapses in the developing brain is not well understood. We used electrophysiology and fluorescence imaging to study GABAergic and glutamatergic synaptogenesis in embryonic hypothalamic cultures, which contain $\sim 40 \%$ GABAergic and $\sim 60 \%$ glutamatergic neurons. The newly dissociated embryonic hypothalamic neurons contained a significant pool of functional $\mathrm{GABA}_{\mathrm{A}}$ receptors but a very low level of glutamate receptors. Within the first week of culture, the time course of GABAergic synaptogenesis in embryonic neurons coincided with that of presynaptic vesicle cycling, but both measurements lagged behind the detection of functional $\mathrm{GABA}_{\mathrm{A}}$ receptors. Remarkably, the $\mathrm{GABA}_{\mathrm{A}}$ receptors of newly dissociated embryonic neurons can be rapidly clustered into postsynaptic apparatus and generate functional synaptic currents within $4-6 \mathrm{~h}$ when cocultured with mature neurons. Consistent with earlier expression of $\mathrm{GABA}_{\mathrm{A}}$ receptors in immature neurons, synaptic GABAergic events were always detected before the onset of glutamatergic events in both purely embryonic and heterochronic cultures. Interestingly, overexpression of glutamate receptors in embryonic neurons not only increased whole-cell glutamate currents but also significantly increased the frequency of excitatory synaptic events. We conclude that the sequential formation of GABAergic and glutamatergic synapses in immature neurons is likely governed by a sequential expression of $\mathrm{GABA}_{\mathrm{A}}$ and glutamate receptors during neuronal development.
\end{abstract}

Key words: GABAergic synapse; $\mathrm{GABA}_{\mathrm{A}}$ receptor; glutamatergic synapse; presynaptic; postsynaptic; culture; hypothalamus

\section{Introduction}

Synapse formation involves a precise coordination of presynaptic and postsynaptic differentiation. Synaptogenesis in the CNS has been extensively studied using a model system of glutamatergic synapses in hippocampal or cortical neurons (Fletcher et al., 1994; Ahmari et al., 2000; Friedman et al., 2000; Ziv and Garner, 2004; Waites et al., 2005). In contrast, the functional assembly of GABAergic synapses is still not well understood.

GABAergic synapses have been detected earlier than glutamatergic synapses during embryonic brain development, but the mechanisms underlying such sequential synapse formation is not

\footnotetext{
Received Feb. 10, 2007; revised Aug. 16, 2007; accepted Aug. 16, 2007.

This work was supported by National Science Foundation Grant 0236429 (G.C.) and National Institutes of Health Grant MH62391 (B.L.). We thank members of the Chen laboratory for vigorous discussion during the progress of this project.

*L.D. and J.Y. contributed equally to this work.

Correspondence should be addressed to Dr. Gong Chen, Department of Biology, 201 Life Sciences Building, The Huck Institutes of Life Sciences, Pennsylvania State University, University Park, PA 16802. E-mail: gongchen@psu.edu.

L. Deng's present address: Center for Basic Neuroscience, University of Texas Southwestern Medical Center, Dallas, TX 75390.

C. Fang's present address: Oregon Health and Science University, Center for Research on Occupational and Environmental Toxicology, L606, 3181 Southwest Sam Jackson Park Road, Portland, OR 97239-3098.

DOI:10.1523/JNEUROSCI.2744-07.2007

Copyright $\odot 2007$ Society for Neuroscience 0270-6474/07/2710860-10\$15.00/0
}

clear (Tyzio et al., 1999; Khazipov et al., 2001; Hennou et al., 2002). Previous studies on GABAergic synapse formation have focused on the clustering of $\mathrm{GABA}_{\mathrm{A}}$ receptors and gephyrin, a putative postsynaptic scaffold protein (Dumoulin et al., 2000; Moss and Smart, 2001; Christie et al., 2002b; Danglot et al., 2003; Luscher and Keller, 2004; Studler et al., 2005). The targeting of $\mathrm{GABA}_{\mathrm{A}}$ receptors to synaptic sites is most likely guided by the $\gamma 2$ subunit as demonstrated by a substantial loss of synaptic $\mathrm{GABA}_{\mathrm{A}}$ receptor clusters in the $\gamma 2^{-1-}$ neurons or with the $\gamma 2$ shRNA assay (Essrich et al., 1998; Baer et al., 2000; Schweizer et al., 2003; Alldred et al., 2005; Li et al., 2005). In addition, $\mathrm{GABA}_{\mathrm{A}}$ receptors can form clusters on cell membranes even before synaptogenesis (Brunig et al., 2002; Christie et al., 2002a; Danglot et al., 2003; Studler et al., 2005). These extrasynaptic $\mathrm{GABA}_{\mathrm{A}}$ receptor clusters are often smaller than those induced by GABAergic nerve terminals (Brunig et al., 2002; Christie et al., 2002a).

Although significant progress has been made about $\mathrm{GABA}_{\mathrm{A}}$ receptor clustering using morphological analysis, much less is known about the functional assembly of GABAergic synapses. In this study, we used functional approaches including patch-clamp recording and FM imaging to examine GABAergic synaptogenesis within a few days or even a few hours after plating embryonic neurons in culture. We detected a significant $\mathrm{GABA}_{\mathrm{A}}$ receptor current but a much smaller glutamate current in newly dissoci- 
A Vesicle Cycling

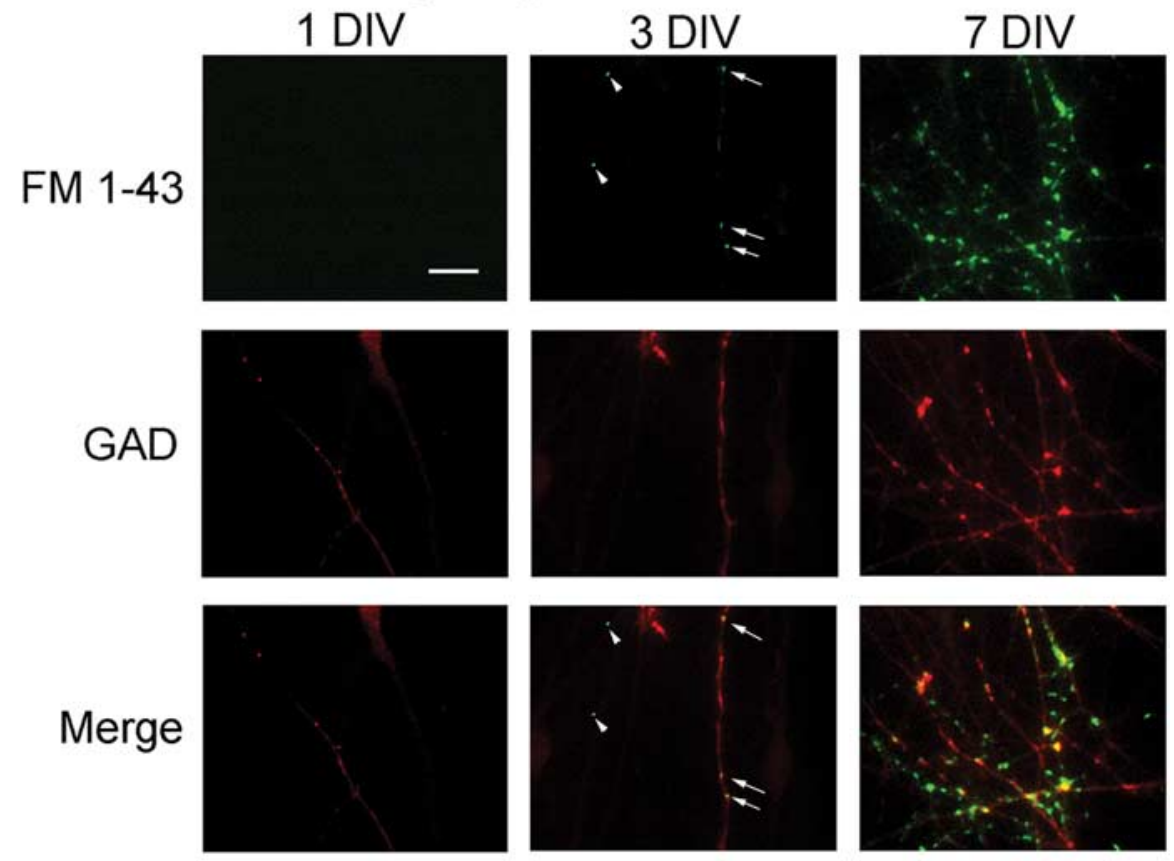

\section{$\mathrm{GABA}_{A}-\mathrm{R}$ Current} 1 DIV

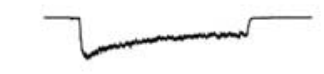

mIPSC

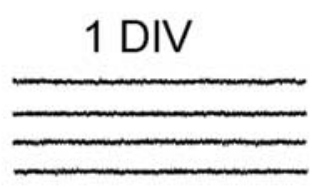

3 DIV

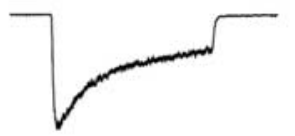

3 DIV



bryonic neurons not only increased whole-cell glutamate currents but also significantly increased the frequency of glutamatergic synaptic events. Therefore, the low expression level of functional glutamate receptors in embryonic neurons may be primarily responsible for the delay of the functional assembly of excitatory synapses.

\section{Materials and Methods}

Cell culture. Hypothalamic cultures were prepared as described previously (Chen et al., 1996). Briefly, medial hypothalamus were dissected out from 15-16 d rat embryos, dissociated by $0.05 \%$ trypsin-EDTA treatment for 30 min, followed by mechanical trituration, and then plated $\left(4000-8000\right.$ cells $\left./ \mathrm{cm}^{2}\right)$ onto coverslips with a monolayer of astrocytes. The culture medium consisted of MEM (Invitrogen, Carlsbad, CA), 5\% FBS (HyClone, Logan, UT), 2\% B-27 supplement (Invitrogen), $100 \mathrm{mg}$ of $\mathrm{NaHCO}_{3}, 20 \mathrm{~mm}$ D-glucose, $0.5 \mathrm{~mm}$ L-glutamine, and $25 \mathrm{U} / \mathrm{ml}$ penicillin/streptomycin. Cultures were maintained in a $5 \% \mathrm{CO}_{2} /$ $95 \%$ air humidified incubator at $37^{\circ} \mathrm{C}$. For heterochronic cultures, a batch of embryonic neurons were first cultured for 2 weeks to function as mature neurons before adding a second batch of freshly dissociated embryonic neurons. To distinguish between young versus mature neurons, newly dissociated neurons were stained in $1 \%$ green fluorescent dye carboxyfluorescein diacetate-succinimidyl ester (CFDA-SE) (Invitrogen) for $15 \mathrm{~min}\left(37^{\circ} \mathrm{C}\right)$ before plating. The dye can be trapped inside cells and last for $>1$ week (Paramore et al., 1992).

Electrophysiology. Single and dual whole-cell recordings were performed using Multiclamp 700A patch-clamp amplifier (Molecular Devices, Palo Alto, CA) (Chen et al., 2003; Deng and Chen, 2003). Patch pipettes were pulled from borosilicate glass and fire-polished (4-6 $\mathrm{M} \Omega$ ). The recording chamber was continuously perfused with a bath solution containing $128 \mathrm{~mm} \mathrm{NaCl}$, $30 \mathrm{~mm}$ glucose, 25 mM HEPES, 5 $\mathrm{mm} \mathrm{KCl,} 2 \mathrm{~mm} \mathrm{CaCl}_{2}, 1 \mathrm{~mm} \mathrm{MgCl}_{2}, \mathrm{pH} 7.3$ adjusted with $\mathrm{NaOH}$. The pipette was filled with a solution consisted of $147 \mathrm{~mm} \mathrm{KCl,} 5 \mathrm{~mm}$ $\mathrm{Na}_{2}$-phosphocreatine, $2 \mathrm{~mm}$ EGTA, $10 \mathrm{~mm}$ HEPES, 4 mM MgATP, 0.5 mm Na $_{2}$ GTP, pH 7.3 adjusted with $\mathrm{KOH}$. The series resistance was typically $10-20 \mathrm{M} \Omega$ and compensated by $40-$ $60 \%$. The membrane potential was held at -70 $\mathrm{mV}$. Data were acquired using pClamp 9 software, sampled at $10 \mathrm{kHz}$, and filtered at $1 \mathrm{kHz}$. Drugs were applied through a fast drug applicaated embryonic hypothalamic neurons [embryonic day 15 (E15) to E16]. The $\mathrm{GABA}_{\mathrm{A}}$ receptors of embryonic neurons can be rapidly clustered into functional postsynaptic apparatus within 4-6 h of contacting by mature GABAergic terminals in heterochronic cultures. These results revealed a very rapid functional assembly of GABAergic synapses that is mostly attributable to a fast formation of functional postsynaptic apparatus. In contrast, the establishment of functional glutamatergic synapses always lagged behind the formation of GABAergic synapses despite the presence of $\sim 60 \%$ glutamatergic neurons in hypothalamic cultures. Interestingly, overexpression of glutamate receptors in em- tion system (VC-6; Warner, Hamden, CT), indicated by the rapid rising phase of whole-cell GABA and AMPA currents (see Figs. 1, 8). Off-line data analysis was done with Clampfit 9 software (Molecular Devices) and MiniAnalysis software (Synaptosoft, Decatur, GA). All data were expressed as mean $\pm \mathrm{SE}$, and Student's $t$ test was used for statistical analysis.

Immunohistochemistry. Cells used for immunofluorescence studies were washed three times in PBS, fixed in 4\% paraformaldehyde for 12 min, and permeabilized for 5 min with $0.2 \%$ Triton in PBS containing $10 \%$ donkey serum. After a brief wash in PBS, cells were incubated with primary antibody overnight at $4^{\circ} \mathrm{C}$ using the following dilutions: mouse anti-GAD-6 (0.5 $\mu \mathrm{g} / \mathrm{ml}$; Developmental Studies Hybridoma Bank, Uni- 
A
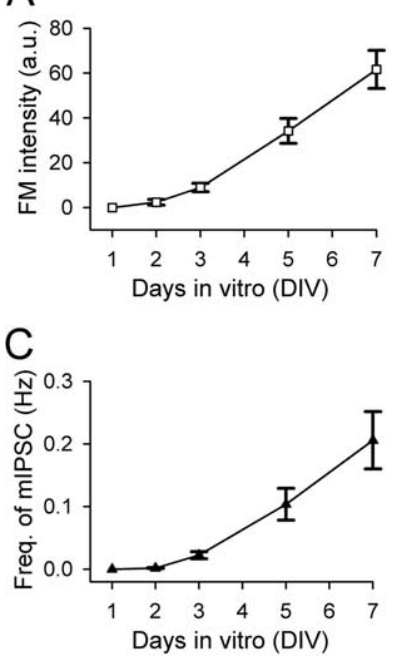

B

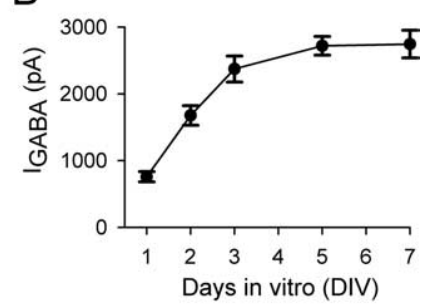

D

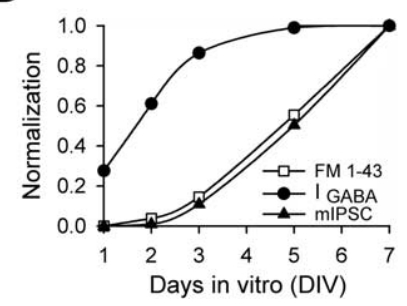

Figure 2. GABAergic synapse formation coincides with presynaptic functional development. $A$, Quantification of developmental changes of the presynaptic FM 1-43 fluorescence intensity during the first week of culture. $B$, Developmental changes of the peak amplitude of whole-cell GABA current. C, Developmental changes of the frequency of mIPSCs, a functional index of GABAergic synaptogenesis. $\boldsymbol{D}$, Overlay of the normalized time courses of presynaptic FM intensity (open square), $G A B A_{A}$ receptor current (filled circle), and mIPSC frequency (filled triangle). Note that the time course of functional GABAergic synapse assembly (mIPSC frequency) appears to match exactly with that of presynaptic development (FM intensity), both with a half-time of $\sim 5$ DIV. In contrast, the time course of the expression of functional $G_{A B A_{A}}$ receptors was left-shifted to a much early time, with a half-time of $<2$ DIV. Data were normalized to the measurements at 7 DIV. Error bars indicate SEM.

versity of Iowa, Iowa City, IA), rabbit anti-GAD65/67 (1:1000; Biomol International, Plymouth Meeting, PA), guinea pig anti- $\gamma 2$ (1:1500) (Fritschy and Mohler, 1995), and mouse anti- $\beta 2 / 3$ (1:5000). For detection of primary antibodies, Alexa Fluor 647-conjugated goat anti-mouse or anti-rabbit (Invitrogen), and Cy3 donkey anti-guinea pig or antimouse (Jackson ImmunoResearch, West Grove, PA) were used as appropriate. Fluorescent images were captured using a Zeiss (Oberkochen, Germany) Axiophot2 microscope equipped with a $40 \times, 1.3$ numerical aperture objective lens and an ORCA-100 video camera linked to an OpenLab imaging system (Improvision, Lexington, MA).

FM 1-43 imaging. FM images were acquired using an inverted Zeiss Axiovert 200 microscope equipped with a Hamamatsu (Hamamatsu, Japan) ORCA-ER cooled CCD camera. Small fluorescent dye FM 1-43 (10 $\mu \mathrm{M}$; Invitrogen) was loaded into presynaptic nerve terminals through activitydependent vesicle cycling induced by membrane depolarization in $90 \mathrm{~mm}$ $\mathrm{KCl}$ solution (2 min) (Ryan et al., 1993; Chen et al., 2003). To identify GABAergic axons after FM 1-43 imaging, cells were fixed with 4\% paraformaldehyde and immunostained with monoclonal antibody against GAD-6, a specific presynaptic marker for GABAergic axons. To quantify FM signal, we relocated the previous FM imaging fields according to the corresponding differential interference contrast images and with the help of markers made on coverslips. After overlaying FM images with L-glutamic acid decarboxylase (GAD) images to identify GABAergic axons, the FM fluorescence intensity was measured with Simple PCI imaging software (Compix, Cranberry Township, PA) along 50-100 $\mu \mathrm{m}$ axon segments with totally $>1000 \mu \mathrm{m}$ of axon length (Chen et al., 2003). Arbitrary units (a.u.) were calculated by dividing the sum of the FM fluorescence intensity by the surface area of the measured axon segments. Each set of experiments were repeated in at least three different batches of cultures.

\section{Results}

\section{Early expression of functional $\mathrm{GABA}_{\mathrm{A}}$ receptors in} embryonic cultures

To study GABAergic synaptogenesis, we used embryonic (E15E16) hypothalamic cultures that are enriched with GABAergic

neurons ( $\sim 40 \%$ ) (Decavel and Van den Pol, 1990; Chen et al., 1996), instead of hippocampal cultures that contain only $\sim 10 \%$ GABAergic neurons (Benson et al., 1994). To investigate how rapidly GABAergic synapses can be functionally established in newly dissociated embryonic neurons, patch-clamp recordings were used to detect the earliest occurring GABAergic events in cultures. By $7 \mathrm{~d}$ in vitro (DIV), GABAergic events can be readily recorded in almost every neuron tested, consistent with previous reports (van den Pol et al., 1998). Therefore, our studies focused on the functional assembly of GABAergic synapses within the first week after plating of embryonic neurons. We started with the examination of three parameters that are closely related to the functional synapse formation: synaptic vesicle cycling in axons, $\mathrm{GABA}_{\mathrm{A}}$ receptor expression on plasma membranes, and the spontaneous miniature IPSCs (mIPSCs).

To assess the functional development of presynaptic terminals, we analyzed synaptic vesicle cycling by monitoring activitydependent uptake of a fluorescent dye FM 1-43 in nerve terminals (Betz and Bewick, 1992; Chen et al., 2003) (Fig. 1A). Functional presynaptic terminals, identified as fluorescent puncta after brief staining with FM 1-43 in $90 \mathrm{~mm} \mathrm{KCl}$ solution (10 $\mu \mathrm{M} ; 2 \mathrm{~min})$, were clearly detected at 3 DIV but rarely at 1-2 DIV (Fig. $1 A$, top row, green puncta), consistent with previous findings (van den Pol et al., 1998). To specifically identify GABAergic terminals, we performed retrospective immunostaining with a specific GABAergic marker GAD, which converts glutamate into GABA (Fig. $1 A$, middle row). GAD immunoreactivity was observed as early as 1 DIV, before the appearance of functional presynaptic terminals. At this time, GAD immunoreactivity was distributed diffusely throughout neurites and soma. At 3 DIV, GAD staining increased and started to form punctate aggregates that often colocalized with FM 1-43-labeled puncta, representing functional GABAergic presynaptic terminals (Fig. $1 \mathrm{~A}$, bottom row, middle panel, arrows). There were also FM 1-43-labeled puncta at 3 DIV that did not colocalize with GAD staining (arrowhead, middle column), which might represent glutamatergic terminals. By 7 DIV, the number of FM-labeled functional presynaptic terminals increased dramatically (Fig. $1 A$, right column).

To assess the expression of functional $\mathrm{GABA}_{\mathrm{A}}$ receptors on the cell membrane of embryonic neurons, we recorded GABA-evoked $(20 \mu \mathrm{M})$ whole-cell currents (Fig. 1B). Interestingly, significant GABA-induced currents $(>600 \mathrm{pA}$ ) were consistently detected at 1 DIV (Fig. $1 B$ ), and even as early as $4-6 \mathrm{~h}$ after plating the embryonic neurons (see below). The amplitude of GABA-induced currents increased substantially from 1 to 3 DIV (>2000 pA) (Fig. $1 B$ ), when most of the presynaptic nerve terminals were not yet functional. After 3 DIV, the developmental change of GABA-evoked currents slowed down, increasing only modestly by 7 DIV (Fig. $1 B$ ). Therefore, the time course of $\mathrm{GABA}_{\mathrm{A}}$ receptor expression on cell membranes appeared to be very different from that of synaptic vesicle cycling in presynaptic axons.

We next evaluated the functional establishment of GABAergic synapses by recording mIPSCs in the presence of TTX $(0.5 \mu \mathrm{M})$ and glutamate receptor antagonist CNQX $(10 \mu \mathrm{M})$. The large majority of neurons tested at 1-2 DIV showed no synaptic events (Fig. 1C), suggesting that few functional synapses are formed at this early stage. The lack of synapse formation cannot be attributed to a lack of axodendritic contacts, because both axons and dendrites have grown a significant length (up to hundreds of micrometers) with significant contacts readily identifiable even at 1 DIV (supplemental Fig. 1, available at www.jneurosci.org as supplemental material). mIPSCs were clearly detected at 3 DIV, coinciding with the appearance of functional presynaptic termi- 



B

\section{Coculture}

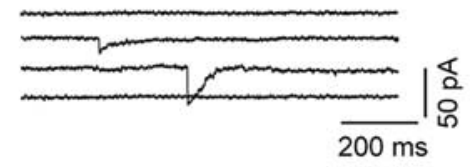

C

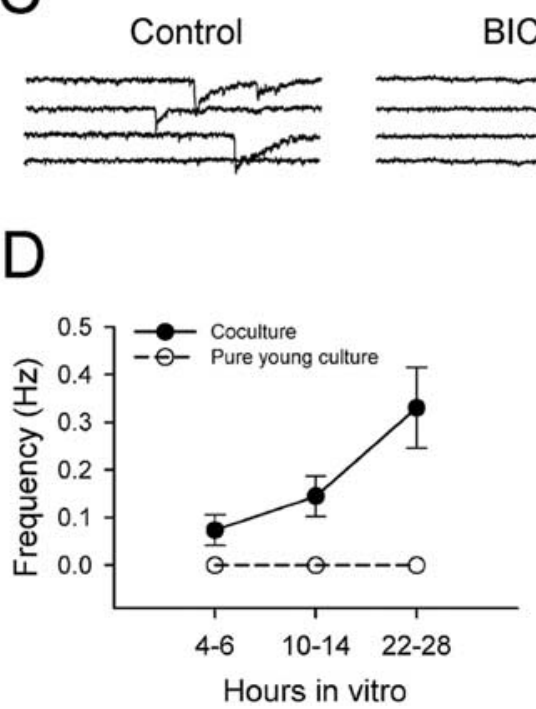

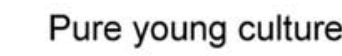

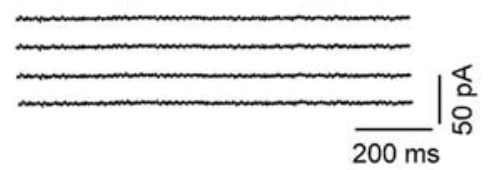

mIPSCs was very low within the first $3 \mathrm{~d}$ $(0.022 \pm 0.006 \mathrm{~Hz}$ at $3 \mathrm{DIV} ; n=28)$, and then rapidly increased from 5 to $7 \mathrm{DIV}$ $(0.21 \pm 0.05 \mathrm{~Hz}$ at $7 \mathrm{DIV} ; n=26)$ (Fig. $2 C)$. Overlay of the three time courses (vesicle cycling, $\mathrm{GABA}_{\mathrm{A}}$ current, and mIPSC frequency), all normalized to the respective measurements at 7 DIV, revealed that functional establishment of GABAergic synapses coincides with that of presynaptic vesicle cycling (Fig. $2 D$ ). In contrast, the time course of $\mathrm{GABA}_{\mathrm{A}}$ receptor currents was significantly left-shifted (Fig. $2 D$ ), indicating a significant expression of functional $\mathrm{GABA}_{\mathrm{A}}$ receptors before GABAergic synaptogenesis. These results led us to hypothesize that the limited synaptic vesicle cycling in presynaptic axons may be a bottleneck for the functional assembly of GABAergic synapses.

One limitation of measuring whole-cell GABA currents is that such currents represent the total number of $\mathrm{GABA}_{\mathrm{A}}$ receptors on cell membranes. How rapidly can the $\mathrm{GABA}_{\mathrm{A}}$ receptors in embryonic neurons be organized into functional postsynaptic apparatus? Because the immature axons of embryonic neurons seemed to develop slower than the $\mathrm{GABA}_{\mathrm{A}}$ receptors, it will be difficult to answer this question using newly dissociated embryonic cultures. Instead, we used a different approach to independently assess the presynaptic versus postsynaptic differentiation during early GABAergic synaptogenesis.

Figure 3. Rapid GABAergic synapse formation in embryonic neurons cocultured with mature neurons. $\boldsymbol{A}$, Coculture of mature (14 DIV; arrows) and (FDA-labeled embryonic neurons (E15-E16; green). Images were taken $24 \mathrm{~h}$ after coculture. Scale bar, 50 $\mu \mathrm{m} . \boldsymbol{B}$, Representative traces showing spontaneous synaptic activity detected in embryonic neurons only $5 \mathrm{~h}$ after coculture. No synaptic events were detected in pure young cultures. $C$, The early detected spontaneous synaptic currents in cocultured embryonic neurons are GABAergic events. All synaptic events were abolished by $\mathrm{GABA}_{\mathrm{A}}$ receptor antagonist BIC (20 $\left.\mu \mathrm{M}\right)$, but not AMPA receptor antagonist CNQX (10 $\mu \mathrm{m})$. D, Pooled data showing a dramatic difference in the frequency of synaptic events between embryonic neurons in coculture (filled circles) and pure young culture (open circles) within $4-28 \mathrm{~h}$ after plating. Error bars indicate SEM. $\boldsymbol{E}$, A significant difference in the percentage of embryonic neurons showing spontaneous synaptic activity between cocultures (filled circles) and pure young cultures (open circles).

nals (Fig. 1, compare $A, C$ ). From 3 to 7 DIV, the frequency of mIPSCs increased dramatically (Fig. 1C), reflecting robust GABAergic synapse formation during this period.

An interesting temporal relationship emerged after we quantitatively examined the early developmental changes of the presynaptic vesicle cycling, the $\mathrm{GABA}_{\mathrm{A}}$ receptor expression, and the frequency of mIPSCs. We estimated the presynaptic vesicle cycling by measuring the total fluorescence intensity of FM 1-43 signal in GAD-immunopositive axons at different days in vitro after plating (Fig. $2 \mathrm{~A}$ ). The FM staining was very low during the first $3 \mathrm{~d}(8.9 \pm 1.9$ a.u. at $3 \mathrm{DIV} ; n=12)$, and then rapidly increased almost sevenfold to $61.6 \pm 8.5$ a.u. by 7 DIV $(n=12)$ (Fig. $2 A$ ). In contrast, the time course of whole-cell GABA currents showed a rapid increase from 1 to 3 DIV (average peak amplitude of $759 \pm 76 \mathrm{pA}$ at $1 \mathrm{DIV}, n=19$; and $2374 \pm 195 \mathrm{pA}$ at $3 \mathrm{DIV}, n=24)$, followed by a much modest change over the next $4 \mathrm{~d}(2746 \pm 207 \mathrm{pA}$ at $7 \mathrm{DIV} ; n=16)$ (Fig. 2 B). Resembling the time course of synaptic vesicle cycling, the frequency of
$\mathrm{GABA}_{\mathrm{A}}$ receptors of embryonic neurons are rapidly assembled into functional postsynaptic apparatus when in contact with mature GABAergic terminals

To assess the presynaptic and postsynaptic differentiation separately in dissociated embryonic neurons, we cocultured immature neurons with mature neurons (14 DIV) together, similar to that reported in hippocampal cocultures (Fletcher et al., 1994). Neurons at 14 DIV showed robust synaptic responses as expected, indicating that both presynaptic and postsynaptic components are fully capable of forming functional synapses. To distinguish newly plated embryonic neurons from cocultured mature neurons, the immature neurons were labeled with a green fluorescent dye, CFDA-SE, before plating (Fig. 3A). Within only $4-6 \mathrm{~h}$ after plating, spontaneous synaptic currents were already detected in cocultured immature neurons with patch-clamp recordings (Fig. $3 B)$. In contrast, no synaptic events were detected in pure young cultures at the same early stage (Fig. $3 B$ ). The spontaneous currents detected at $4-6 \mathrm{~h}$ after coculture were completely abolished by $\mathrm{GABA}_{\mathrm{A}}$ receptor-specific antagonist bicuculline (BIC) (20 $\mu \mathrm{M})$, but not by glutamate receptor antagonist CNQX $(10 \mu \mathrm{M})$ (Fig. 3C). These results indicate that the earliest synaptic events in cocultured immature neurons are almost exclusively GABAergic. The frequency of spontaneous synaptic currents recorded from cocultured immature neurons increased fivefold from $0.07 \pm$ 
$0.03 \mathrm{~Hz}(n=14)$ at $4-6 \mathrm{~h}$ to $0.33 \pm 0.08 \mathrm{~Hz}(n=13)$ at $22-28 \mathrm{~h}$ after plating, suggesting that early synaptic events at $4-6 \mathrm{~h}$ are not a transient phenomenon (Fig. 3D, filled circles). The percentage of cocultured immature neurons showing spontaneous synaptic activity also increased significantly during the first $28 \mathrm{~h}$ of coculture and reached $90 \%$ at 1 DIV (Fig. $3 E$, filled circles). In contrast, no synaptic events were observed in pure young cultures over the same culture period (Fig. $3 D$, E, open circles). These results indicate that $\mathrm{GABA}_{\mathrm{A}}$ receptors in newly dissociated embryonic neurons can be rapidly organized into functional postsynaptic apparatus and respond to presynaptic GABA release.

To address whether rapid GABAergic synapse formation in cocultured immature neurons was associated with an increase in functional $\mathrm{GABA}_{\mathrm{A}}$ receptors, we compared whole-cell GABA currents in pure young and heterochronic cultures. Bath application of GABA $(20 \mu \mathrm{M})$ induced similar whole-cell currents in immature neurons at $4-6 \mathrm{~h}$ after plating from both cocultures $(506.9 \pm 66.0 \mathrm{pA} ; n=12)$ and pure young cultures $(560.2 \pm 71.2$ $\mathrm{pA} ; n=14 ; p>0.5)$. The average peak amplitude of GABA currents measured at 10-14 h was also not different between cocultures $(654 \pm 63.2 \mathrm{pA} ; n=15)$ and pure young cultures $(639.5 \pm 45.0 \mathrm{pA} ; n=14 ; p>0.8)$. Therefore, rapid GABAergic synaptogenesis in immature neurons cocultured with mature neurons (within 4-14 h) cannot be attributed to increased expression of $\mathrm{GABA}_{\mathrm{A}}$ receptors. At $22-28 \mathrm{~h}$ after plating, we found that the response to GABA in cocultured immature neurons was significantly increased (1088.1 $\pm 82.6 \mathrm{pA} ; n=19)$ compared with the pure young cultures $(758.8 \pm 69.3 \mathrm{pA} ; n=19 ; p<0.01)$. Thus, in addition to inducing rapid postsynaptic clusters of $\mathrm{GABA}_{\mathrm{A}}$ receptors, mature neurons may also promote the expression of $\mathrm{GABA}_{\mathrm{A}}$ receptors in cocultured immature neurons.

In early heterochronic cultures, GABA release is likely coming from mature GABAergic terminals, but we cannot exclude the possibility that mature neurons might facilitate synapse formation among immature neurons. To test the effect of mature neurons, we cultured newly dissociated embryonic neurons in the medium collected from mature cultures (at 14 DIV). No significant increase of detectable synaptic events in pure young cultures grown in conditioned medium was observed (supplemental Fig. 2 , available at www.jneurosci.org as supplemental material). Addition of GABA $(5 \mu \mathrm{M})$ to the culture medium of pure young cultures also had no significant effect on synapse formation (supplemental Fig. 2, available at www.jneurosci.org as supplemental material). Conversely, addition of TTX $(0.5 \mu \mathrm{M})$ into culture medium right before plating the embryonic neurons to block action potentials in the heterochronic cultures did not reduce the number of synaptic events recorded from immature neurons (supplemental Fig. 2, available at www.jneurosci.org as supplemental material). These results suggest that the rapid formation of GABAergic synapses in cocultured immature neurons is not attributable to secreted factors or ongoing neuronal activity in mature cultures.

We next investigated whether the presynaptic terminals of cocultured immature neurons are functional at a time when spontaneous IPSCs were readily detected in immature neurons (24-28 h). Dual whole-cell recordings were performed on mature-immature or immature-immature pairs of neurons to examine whether electrical stimulation can evoke immature axonal release after $1 \mathrm{~d}$ in coculture. Figure $4, A-C$, illustrates a typical dual whole-cell recording of a mature-immature pair of neurons (Fig. $4 A$ ). A brief depolarization pulse ( -70 to $0 \mathrm{mV} ; 1.5 \mathrm{~ms}$ ) applied to the mature neuron evoked IPSCs in both the mature neuron itself and the paired immature neuron (Fig. 4B) (both

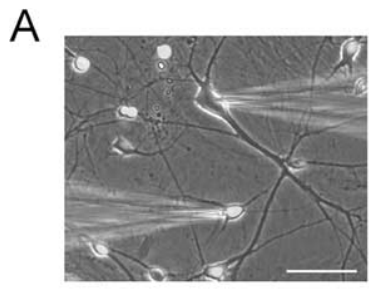

B
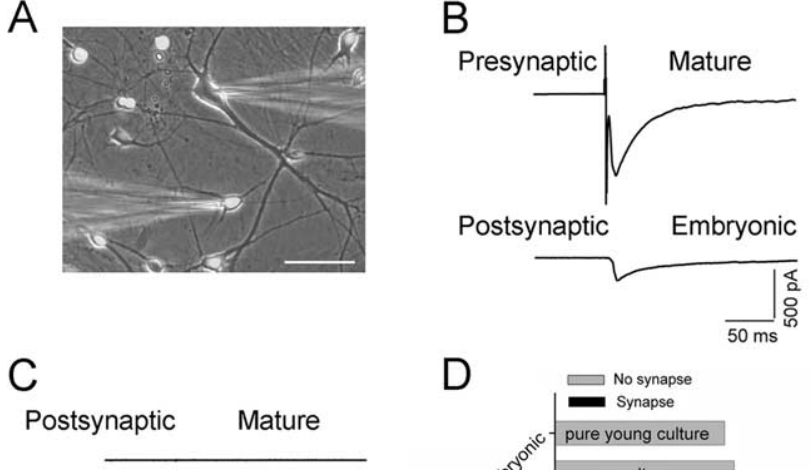

D
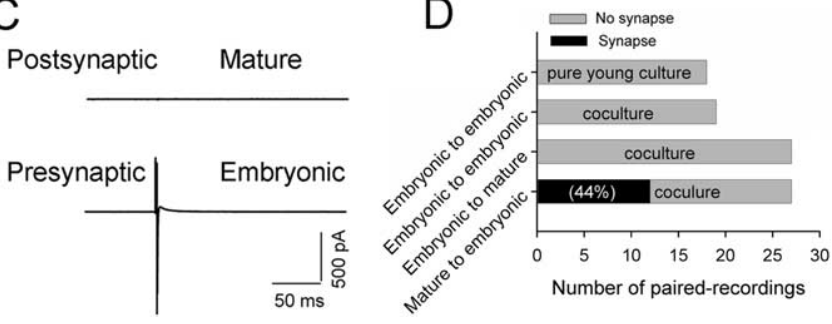

Figure 4. $G_{A B A_{A}}$ receptors in cocultured embryonic neurons are rapidly assembled into functional postsynaptic apparatus on innervation by mature GABAergic axon terminals. $A, 0$ verlay of a fluorescent and a phase-contrast image showing dual whole-cell recording on a pair of mature (top electrode) and embryonic (bottom electrode) neurons ( $24 \mathrm{~h}$ after plating). Scale bar, $50 \mu \mathrm{m}$. $\boldsymbol{B}$, Stimulating a mature neuron (serving as presynaptic) evoked IPSCs in both mature and embryonic neurons. $\boldsymbol{C}$, Stimulating the embryonic neuron in the same pair resulted in no synaptic responses in either mature or embryonic neurons. Note that no electrically coupled current was detected in the mature neuron, suggesting no gap junction coupling between the paired neurons. $D$, Bar graphs summarizing the number of paired recordings with or without synaptic coupling in both cocultures and pure young cultures (22-28 $\mathrm{h}$ after plating). Synaptic responses in embryonic neurons can be recorded only when stimulating mature neurons. Gray bar, No evoked synaptic responses; black bar, evoked synaptic responses.

blocked by $20 \mu \mathrm{M}$ BIC) (data not shown). However, stimulating the immature neuron did not evoke any synaptic currents, neither in itself nor in the paired mature neuron (Fig. 4C). Note that despite the large action current in the stimulated immature neuron, there was no corresponding current observed in the paired mature neuron, indicating no electrical coupling between the two neurons. Indeed, stimulation of immature neurons (1 DIV) in immature-mature $(n=27)$ or immature-immature pairs $(n=$ 18) never resulted in any evoked synaptic responses, suggesting that immature axons are not functional after $1 \mathrm{~d}$ in coculture (Fig. $4 D$ ). In contrast, when stimulating mature neurons, evoked IPSCs were recorded in $>40 \%$ of cocultured immature neurons ( 12 of 27 pairs), demonstrating that immature neurons are postsynaptically ready to receive GABAergic innervation from mature neurons. We did not detect any spontaneous or evoked EPSCs in cocultured immature neurons at $1 \mathrm{DIV}$, consistent with an early GABAergic synaptogenesis observed in vivo (Tyzio et al., 1999). The 15 matureimmature pairs that did not show any synaptic responses when stimulating mature neurons either could be attributable to no synaptic connections between the paired neurons or the mature neurons might be glutamatergic and therefore not able to induce any EPSCs in immature neurons at 1 DIV.

Because stimulating mature neurons evoked IPSCs in both mature and immature neurons, we wondered to what extent the newly formed GABAergic synapses on immature neurons (1 DIV) might be functionally similar to that formed on mature neurons. Figure 5 illustrates the analysis of the peak amplitude as well as short-term plasticity of GABAergic responses recorded from mature versus immature neurons. A paired recording of the IPSCs in mature and immature neurons is illustrated in Figure 5, $A$ and $B$. After stimulating mature neurons, the evoked IPSCs recorded from immature neurons were small and showed a large 
A

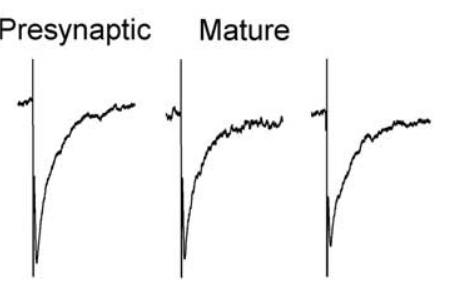

Postsynaptic Immature
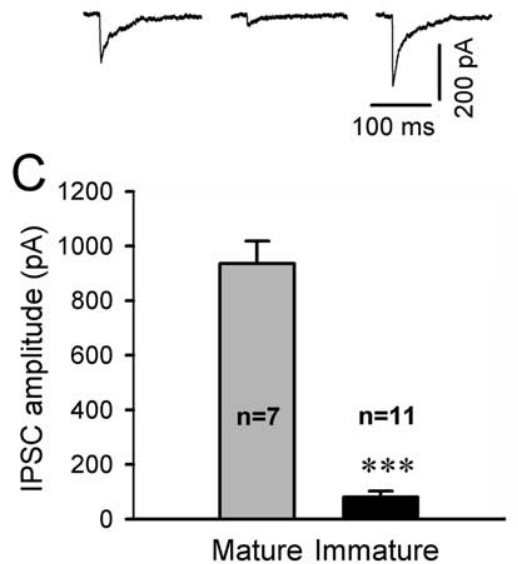
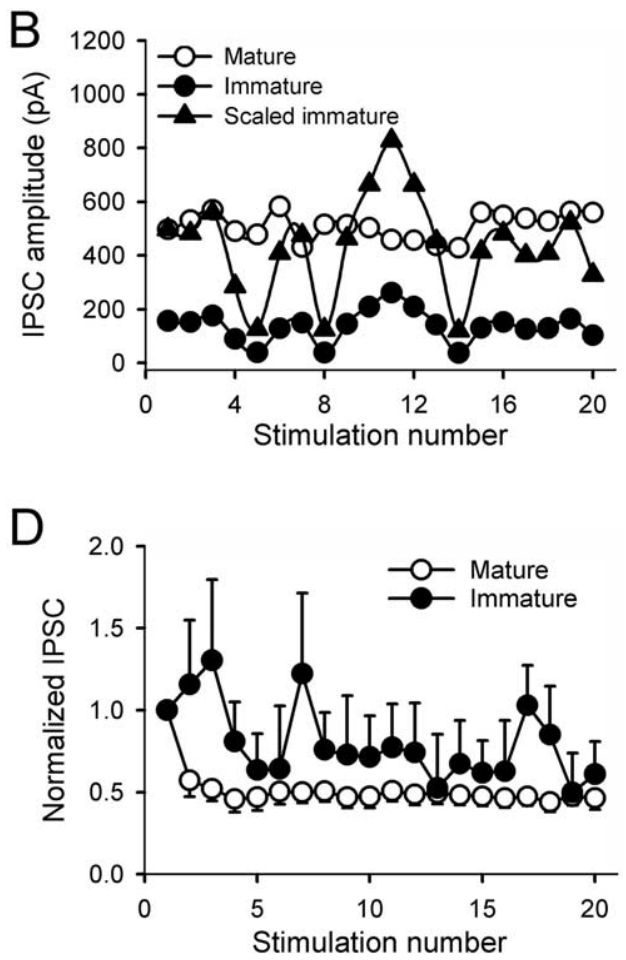

Figure 5. Comparison of synaptic properties between synapses formed from mature-to-mature neurons and mature-toembryonic neurons. A, Stimulating a mature neuron with low frequency repetitive stimulation $(0.1 \mathrm{~Hz} ; 20$ stimuli) evoked autaptic IPSCs in itself (top row) and heterosynaptic IPSCs in a paired embryonic neuron (bottom row). Note that the amplitude of IPSCs in the mature neuron is quite stable, whereas the amplitude of IPSCS in the embryonic neuron has large variation. $\boldsymbol{B}$, Scaled amplitudes of evoked IPSCs in the immature neuron (filled triangle) showed a large variation and did not match the amplitude of IPSCs in the mature neuron (open circle). Filled circle, The original amplitudes of IPSCs in the immature neuron. C, Comparison of the average amplitude of the evoked IPSCs in mature versus immature neurons $\left({ }^{* * *} p<0.001\right)$. D, Plot of normalized amplitudes of a train of IPSCs versus the stimulation number in both mature and immature neurons. The IPSCs in the mature neuron (open circle) showed significant short-term synaptic depression, whereas the IPSCs in the immature neuron (filled circle) showed an initial facilitation followed by a depression that also displayed a large variation during train stimulation. Error bars indicate SEM.

variation, suggesting a small number of synapses formed onto immature neurons (Fig. 5A). When plotting the IPSC amplitude versus stimulation number (Fig. $5 B$ ), the IPSCs from mature neurons (open circle) were very stable, whereas the scaled IPSCs from immature neurons (filled triangle) showed a large variation. The absence of a correlation between the mature and immature IPSCs also confirmed that the two neurons were not coupled via gap junctions. The average amplitude of IPSCs recorded from mature neurons ( $936.7 \pm 82.5 \mathrm{pA} ; n=7$ ) was much larger than that recorded from cocultured immature neurons $(80.4 \pm 22.0$; $n=11 ; p<0.001$ ) (Fig. 5C). To investigate the short-term synaptic plasticity of mature versus immature synapses, we applied a train of stimulation $(10 \mathrm{~Hz} ; 20$ stimuli) to the mature neurons to evoke synaptic transmission. Most of the IPSCs recorded from mature neurons $(n=6)$ showed a short-term synaptic depression during the train stimulation (open circles) (Fig. 5D). In contrast, immature neurons $(n=6)$ showed a facilitation during the initial train stimulation, suggesting a low presynaptic release probability in the newly formed synapses (Zucker and Regehr, 2002) (Fig. $5 D)$.

We further examined rapid GABAergic synapse formation in cocultured embryonic neurons using double immunofluorescent staining with antibodies specific for the presynaptic marker GAD and the postsynaptic $\mathrm{GABA}_{\mathrm{A}}$ receptors $\gamma 2$ and $\beta 2 / 3$ subunits. Pure young cultures (1 DIV) lacked punctate immunoreactivity for the $\gamma 2$ subunit or GAD, indicating a lack of synaptic develop- ment (Fig. 6, top row). Occasionally, some very small $\gamma 2$ puncta $(<0.5 \mu \mathrm{m}$ in diameter) were found on somata or dendrites of embryonic neurons but they were not colocalized with punctate GAD immunoreactivity (Fig. 6, top row, arrowhead). Such punctate $\mathrm{GABA}_{\mathrm{A}}$ receptor immunoreactivity is likely representing $\mathrm{GABA}_{\mathrm{A}}$ receptor clusters that formed before synaptogenesis (Christie et al., 2002a; Studler et al., 2005). In contrast, immunostaining of cocultures revealed many GAD-positive puncta that were juxtaposed to punctate $\gamma 2$ subunit staining, most of which was localized on mature neurons as expected. Importantly, punctate $\gamma 2$ subunit immunoreactivity was also detected in CFDAlabeled embryonic neurons $1 \mathrm{~d}$ after plating in coculture, and some of these puncta were large $(>1 \mu \mathrm{m}$ in diameter) and juxtaposed to presynaptic GAD immunoreactivity (Fig. 6, middle row). In addition, when we performed immunostaining with antibodies specific for $\mathrm{GABA}_{\mathrm{A}}$ receptor $\beta 2 / 3$ subunits, we also found similar large puncta colocalizing with GAD in cocultured embryonic neurons (Fig. 6, bottom row). These immunofluorescence studies confirmed rapid GABAergic synapse formation in embryonic neurons that were cocultured with mature neurons.

In summary, newly dissociated embryonic neurons can respond to a mature neuronal contact by rapidly clustering $\mathrm{GABA}_{\mathrm{A}}$ receptors and forming functional GABAergic synapses all within a few hours. However, no EPSCs were detected in immature neurons within $1 \mathrm{~d}$ coculture, suggesting a delay of glutamatergic synaptogenesis even in heterochronic cultures.

\section{Embryonic neurons express a low level of functional glutamate receptors}

Why were the earliest synaptic events detected in our embryonic hypothalamic cultures always GABAergic but not glutamatergic? To understand the molecular mechanisms governing such sequential formation of GABAergic and glutamatergic synapses, we examined spontaneous postsynaptic currents (sPSCs) in the absence of TTX to increase the sensitivity for the detection of synaptic events (Fig. 7). Despite the absence of TTX, very few synaptic events were recorded at 1 DIV and all of them were slow decaying GABAergic events (Fig. 7A). By 3 DIV, in some embryonic neurons, there were a significant number of sPSCs that showed two distinct decay phases: one very slow $(\tau=9-18 \mathrm{~ms}$; filled circle) and the other very fast ( $\tau=2-5 \mathrm{~ms}$; open triangle) (Fig. 7A). The slow events were all abolished by BIC $(20 \mu \mathrm{M})$, whereas the few fast events were blocked by CNQX $(10 \mu \mathrm{M})$ (data not shown), indicating that glutamatergic events appeared at 3 DIV. Quantification of the frequency of sIPSCs versus sEPSCs in the same neurons confirmed that sIPSCs were far more frequent than sEPSCs in the early days of embryonic cultures (Fig. 7B) (no sEPSCs at 1 DIV; $p<0.02$ at 2 DIV; $p<0.001$ at 3 DIV; $n=$ 12-16).

We next investigated whether glutamate receptors are ex- 


\section{Pure young culture}
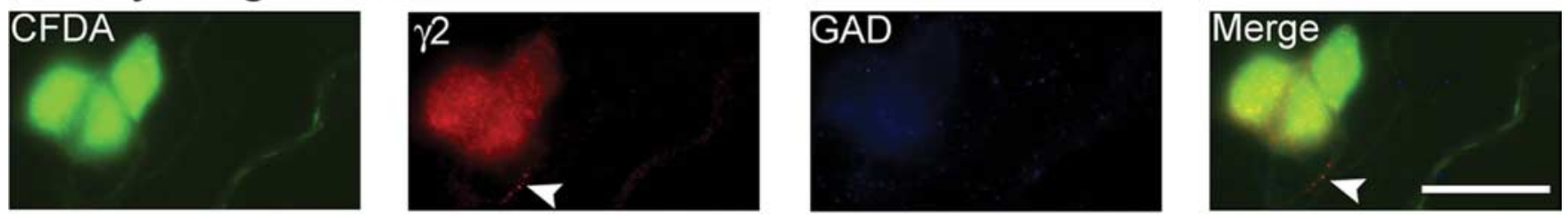

\section{Coculture}
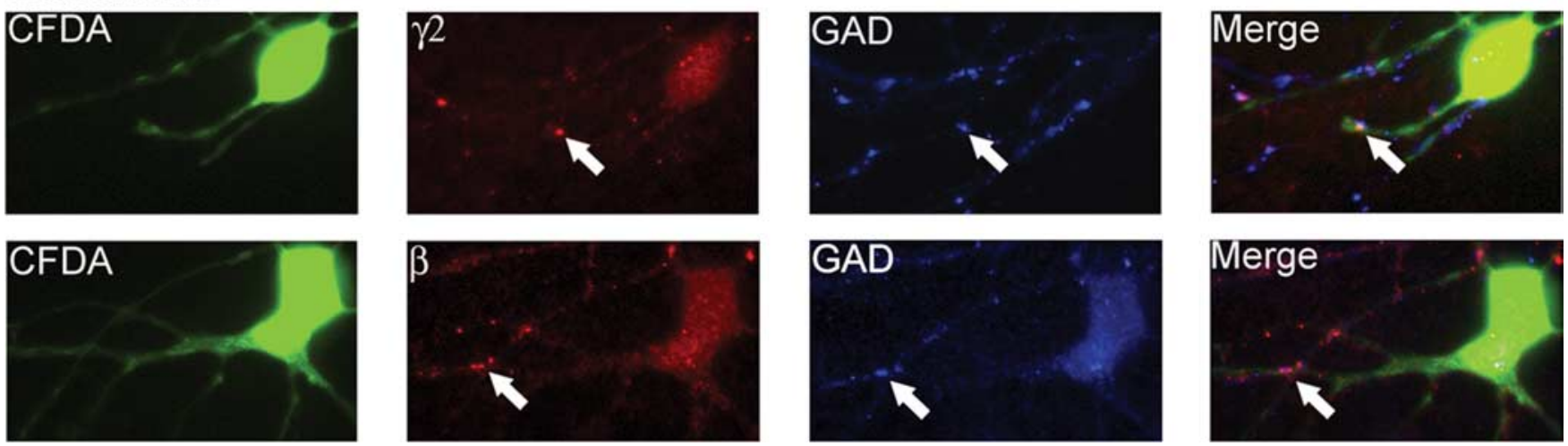

Figure 6. Immunofluorescence staining reveals rapid formation of morphological GABAergic synapses in cocultured embryonic neurons. Top row, Immunostaining in pure young cultures (1 DIV). Embryonic neurons were labeled with CFDA (green) before plating, and double immunostained with GABA receptor $\gamma 2$ subunit (red) and GABAergic presynaptic marker GAD (blue) antibodies. The $\gamma 2$ subunits were diffusely distributed on somadendritic membranes, except a few small puncta occasionally observed (arrowhead). Middle and bottom rows, Immunostaining in cocultures (1 DIV). Middle row, Double immunostaining revealed large $\gamma 2$ puncta (arrow) in (FDA-labeled embryonic neurons that were colocalized with GAD puncta (arrow). Bottom row, Immunostaining with antibodies specific for $\mathrm{GABA}_{\mathrm{A}}$ receptor $\beta$ subunit (red) also revealed large puncta colocalized with GAD puncta (blue) in CFDA-labeled embryonic neurons. Scale bar, $20 \mu \mathrm{m}$.

pressed in the early days after plating embryonic neurons. Rapid bath application of glutamate $(500 \mu \mathrm{M})$ or GABA $(20 \mu \mathrm{M}$, for comparison) was used to elicit whole-cell currents in the same neurons. The sequence of application of glutamate and GABA was alternated in different neurons, and no significant effect of the order of application was observed. Whereas a significant GABA current was recorded in every neuron tested starting from 1 DIV, the glutamate current was barely detectable at 1-3 DIV (Fig. 7C, 3 DIV). Even by 5 DIV, the glutamate current remained very small (100-300 pA) (Fig. 7D). Therefore, we hypothesize that comparing with GABAergic synaptogenesis, the significant delay of glutamatergic synapse formation in embryonic hypothalamic neurons is likely attributable to a very low expression level of functional glutamate receptors.

Enhancing glutamate receptor expression increases excitatory synaptic events

To test our hypothesis that the lack of glutamatergic synaptic events in cultured immature neurons is attributable to the limitation of glutamate receptor expression, we increased the expression level of AMPA receptors in embryonic neurons by transfection of glutamate receptor subunits GluR1 and GluR2. The transfection was performed at the second day after plating using our improved $\mathrm{Ca}^{2+}$-phosphate transfection method (Jiang and Chen, 2006). Two days after transfection (4 DIV), patch-clamp recordings were conducted to analyze AMPA receptor currents as well as synaptic responses in both transfected and nontransfected neurons. As expected, the whole-cell AMPA $(100 \mu \mathrm{M})$ currents were significantly increased in neurons transfected with GluR1/2 subunits $(218.8 \pm 24.0 \mathrm{pA} ; n=16)$ in comparison with the nontransfected neighboring neurons $(94.6 \pm 12.5 \mathrm{pA} ; n=16$; $p<0.001$ ) (Fig. $8 A, B)$. To investigate the effect of increasing AMPA receptor expression on synaptic responses, we recorded both spontaneous EPSCs and IPSCs in transfected and nontransfected neurons (Fig. 8C,D). The amplitude of sEPSCs showed no significant change after transfection (control, $12.4 \pm 1.1 \mathrm{pA}, n=$ 17; GluR1/2-transfected, $14.0 \pm 0.9 \mathrm{pA}, n=18 ; p>0.27$ ). However, the frequency of sEPSCs significantly increased in GluR1/2transfected neurons $(0.65 \pm 0.09 \mathrm{~Hz} ; n=18)$ compared with the nontransfected controls $(0.22 \pm 0.04 \mathrm{~Hz} ; n=17 ; p<0.001)$. In contrast, there was no difference between the sIPSCs recorded from transfected and nontransfected neurons in terms of both amplitude (control, $28.4 \pm 3.3 \mathrm{pA}, n=17$; GluR1/2-transfected, $30.6 \pm 4.1 \mathrm{pA}, n=18 ; p>0.68$ ) and frequency (control, $0.50 \pm$ $0.13 \mathrm{~Hz}, n=17$; GluR1/2-transfected, $0.55 \pm 0.14 \mathrm{~Hz}, n=18$; $p>0.76$ ). Therefore, increasing the expression level of glutamate receptors in embryonic neurons can effectively increase the number of glutamatergic synaptic events. These results support our hypothesis that low level of glutamate receptor expression may be a limiting factor in the delayed glutamatergic synapse assembly.

In addition to AMPA receptors, NMDA receptors are another major subtype of ionotropic glutamate receptors. We further examined the functional expression of NMDA receptors and NMDA receptor-mediated EPSCs in hypothalamic embryonic cultures. To record NMDA receptor-mediated responses, we removed $\mathrm{Mg}^{2+}$ from bath solution and added coactivator glycine $(1-10 \mu \mathrm{M})$. As shown in Figure 9, $A$ and $B$, the expression level of NMDA receptors is also very low in embryonic neurons, with a peak amplitude of the whole-cell NMDA $(100 \mu \mathrm{M})$ currents at only $105.6 \pm 12.2 \mathrm{pA}$ ( $3 \mathrm{DIV} ; n=18)$. In contrast, the same set of neurons showed large whole-cell GABA currents $(1641 \pm 101$ $\mathrm{pA} ; n=18 ; p<0.001)$. When sEPSCs were recorded from immature neurons ( $3 \mathrm{DIV}$ ) in $\mathrm{Mg}^{2+}$-free solution with the addition of glycine and $\mathrm{GABA}_{\mathrm{A}}$ receptor antagonist picrotoxin $(100 \mu \mathrm{M})$, the occurrence of NMDA EPSCs was also very low in frequency, often after rapid decaying AMPA EPSCs (Fig. 9C). In contrast, 
A



B
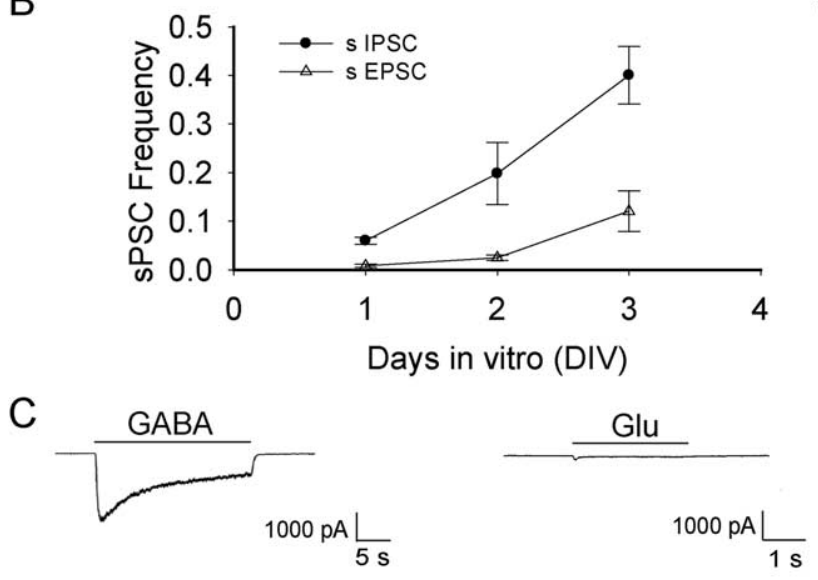

D

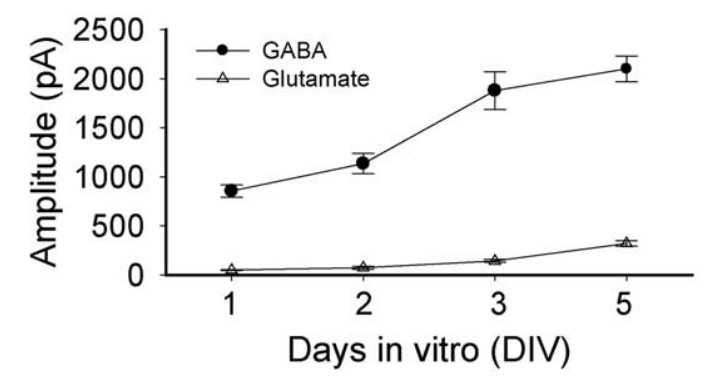

Figure 7. Low expression level of functional glutamate receptors and a delay of glutamatergic synapse formation in embryonic neurons. $A$, Spontaneous synaptic currents recorded in pure young cultures within the first $3 \mathrm{~d}$ after plating. Both sEPSCS (open triangle) and sIPSCS (filled circle) were recorded at 3 DIV. № TTX was included in the recording solution. B, Quantification of the frequency of sIPSCS (filled circle) versus that of SEPSCs (open triangle) showed much less glutamatergic responses comparing to GABAergic responses. $n=12-16$ for each data point. $C$, Typical recording of whole-cell currents induced by GABA $(20 \mu \mathrm{m})$ versus glutamate $(500 \mu \mathrm{m})$ in embryonic neurons (3 DIV). Note the small current induced by glutamate application comparing to the large GABA current at the same age neurons. $D$, Developmental changes of the peak amplitude of glutamate currents (open triangle) versus GABA currents (filled circle). Clearly, the expression of functional glutamate receptors is very limited in dissociated embryonic neurons. Error bars indicate SEM.

the same age neurons often showed much higher frequency of sIPSCs (Fig. 9C). To demonstrate that the low frequency of sEPSCs in our embryonic hypothalamic cultures is not attributable to abnormal conditions, we further recorded sEPSCs in mature neurons (15 DIV) under the same recording condition. As expected, both the AMPA and NMDA EPSCs showed much higher frequency in mature neurons than that in immature neurons (Fig. 9D). Accordingly, we also found that in mature neurons (15 DIV), the whole-cell AMPA ( $826 \pm 95 \mathrm{pA} ; n=16)$ and NMDA currents $(724 \pm 75 \mathrm{pA} ; n=16)$ were much larger than those of immature neurons $(\sim 100 \mathrm{pA})$ (Figs. $8 B, 9 B)$.

Together, we conclude that the expression level of functional receptors in immature neurons may play a key role in determining the time course of synaptogenesis.



Figure 8. Overexpression of GluR1/2 increases whole-cell AMPA receptor currents and spontaneous EPSC frequency in embryonic neurons. $A$, Typical recordings of whole-cell currents induced by AMPA $(100 \mu \mathrm{M})$ in embryonic neurons without (top trace) or with GluR1/2 overexpression (bottom trace). Transfection was performed on 2 DIV and recording was on 4 DIV. $\boldsymbol{B}$ Pooled data showing a significant increase of the peak amplitude of AMPA currents in embryonic neurons after GluR1/2 overexpression (*** $p<0.001$ ). Error bars indicate SEM. C, Spontaneous EPSCS and IPSCS recorded from nontransfected control neurons. D, Spontaneous EPSCS and IPSCS recorded from neurons transfected with GluR1/2. The frequency of spontaneous EPSCS was significantly increased after overexpression of GluR1/2 in embryonic neurons ( $n=$ $18 ; p<0.001)$. The sIPSC $s$ were not affected after transfection of GluR1/2. The open triangles indicate EPSCs. The filled circles label IPSCS.

\section{Discussion}

There are two major findings interrelated with each other in this study: First, functional $\mathrm{GABA}_{\mathrm{A}}$ receptors are expressed early in dissociated embryonic neurons and these $\mathrm{GABA}_{\mathrm{A}}$ receptors can be rapidly organized into functional postsynaptic apparatus to respond to GABA release. Second, sequential expression of functional $\mathrm{GABA}_{\mathrm{A}}$ and glutamate receptors may be the key factor in governing the order of GABAergic and glutamatergic synapse formation during neuronal development. Using a functional approach of patch-clamp recording, we investigated the functional assembly of GABAergic versus glutamatergic synapses from hours to days after plating dissociated embryonic neurons in culture. Our results demonstrate that dissociated embryonic neurons contain a significant reservoir of functional $\mathrm{GABA}_{\mathrm{A}}$ receptors that is preceding the synaptic vesicle cycling in presynaptic axons. In contrast, the immature neurons do not express high level of functional glutamate receptors within the first few days after plating, which may explain why glutamatergic synapse formation significantly lags behind GABAergic synaptogenesis. Importantly, we further demonstrated that overexpressing glutamate receptors can significantly increase the number of excitatory synaptic events in dissociated embryonic neurons. These results suggest that the expression level of functional receptors may play a critical role in determining the time sequence of GABAergic versus glutamatergic synaptogenesis in immature neurons.

The most striking evidence for rapid GABAergic synaptogenesis comes from the analysis of heterochronic cultures of mature and immature neurons. We found that mature GABAergic neurons can rapidly innervate immature neurons and induce spontaneous as well as evoked IPSCs within $24 \mathrm{~h}$ of coculture, indicating that immature neurons can rapidly form functional postsynaptic $\mathrm{GABA}_{\mathrm{A}}$ receptor clusters to detect $\mathrm{GABA}$ release. In 
A
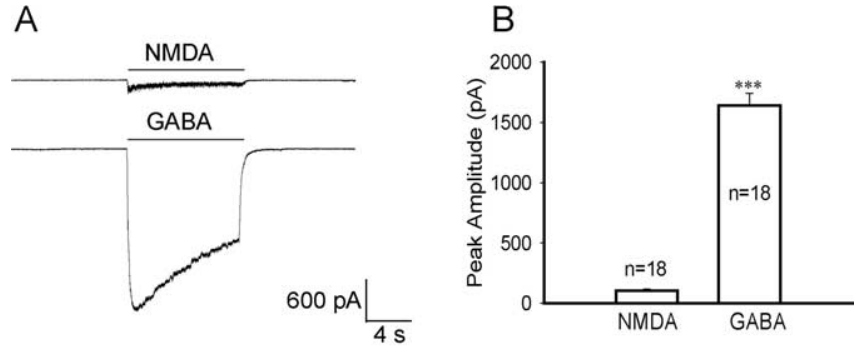

C 3 DIV

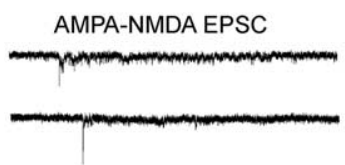

AMPA EPSC
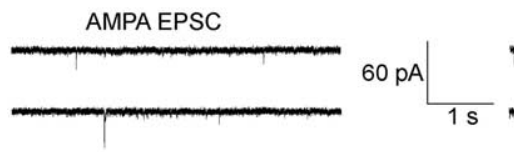

D 15 DIV

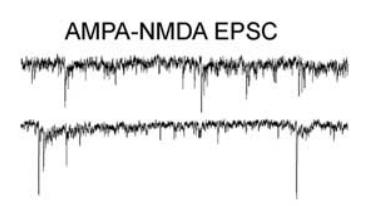

AMPA EPSC
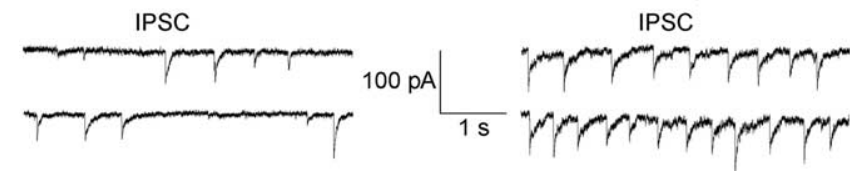

Figure 9. The expression level of NMDA receptors is very low in embryonic hypothalamic cultures. $\boldsymbol{A}$, Typical recordings of whole-cell currents induced by NMDA $(100 \mu \mathrm{M})$ or GABA (20 $\mu \mathrm{M}$ ) in embryonic neurons at 3 DIV. $\boldsymbol{B}$, Summarized data of the peak amplitude of whole-cell NMDA and GABA currents in embryonic neurons at 3 DIV $\left({ }^{* * *} p<0.001\right)$. Error bars indicate SEM. C, Representative traces of spontaneous AMPA-NMDA EPSCS, AMPA EPSCS, and IPSCs in immature neurons (3 DIV). AMPA-NMDA responses were recorded in the presence of $G_{A B A_{A}}$ receptor antagonist picrotoxin (PTX) $(100 \mu \mathrm{m})$ in $\mathrm{Mg}^{2+}$-free solution. Note the sparse NMDA EPSCS, which often follow AMPA EPSCS as expected. AMPA EPSCs alone were recorded in the presence of PTX (100 $\mu \mathrm{m})$ plus AP5 $(50 \mu \mathrm{M})$ to block NMDA receptors. IPSCs were recorded in the presence of NBQX (5 $\mu \mathrm{m}$; blocking AMPA receptors) and AP5 $(50 \mu \mathrm{m})$. D, Typical traces illustrating the spontaneous AMPA-NMDA EPSCS, AMPA EPSCs, and IPSCs in mature neurons (15 DIV). Note a substantial increase in both NMDA and AMPA EPSCs after neuronal maturation.

contrast, immature presynaptic axons are not capable of establishing GABAergic synapses either on mature neurons or on adjacent immature neurons after $1 \mathrm{~d}$ coculture. These results suggest that the presynaptic maturation is slower than that of postsynaptic maturation during early GABAergic synaptogenesis. Indeed, we have recently demonstrated that even in 1-weekold hippocampal cultures, many presynaptic terminals are still functionally silent (Yao et al., 2006), consistent with a slow time course of presynaptic functional maturation. A rapid formation of GABAergic postsynaptic apparatus and slower presynaptic differentiation in the embryonic neurons explains why the functional establishment of GABAergic synapses coincides with that of presynaptic vesicle cycling (Fig. $2 D$ ). It suggests that, once a presynaptic GABAergic terminal becomes functional, a functional GABAergic synapse will be established shortly thereafter.

The molecular assembly of GABAergic synapses may be quite different from that of glutamatergic synapse assembly. We demonstrated that the formation of glutamatergic synapses always lags behind that of GABAergic synapses despite that the majority of hypothalamic neurons are glutamatergic (60\%) (van den Pol and Trombley, 1993). In contrast to a significant expression of functional $\mathrm{GABA}_{\mathrm{A}}$ receptors in acutely dissociated embryonic neurons, the expression level of functional glutamate receptors is very low, even after 3-5 DIV (Fig. 7D). The small glutamate cur- rent in embryonic neurons is unlikely explained by a slow recovery of glutamate receptors after enzymatic dissociation because any loss of membrane surface receptors should be recovered by 24-48 h (Ehlers, 2000). The fact that the glutamate current remained very small at 3-5 DIV suggests that the expression of glutamate receptors is kept at a low level in immature neurons, but increases significantly during neuronal development as shown by large AMPA and NMDA currents in mature neurons (15 DIV). The lack of glutamatergic events in immature neurons is also unlikely explained by a lack of dendrites (supplemental Fig. 1, available at www.jneurosci.org as supplemental material). Therefore, the low expression level of functional glutamate receptors may at least be one of the major causes for the lack of functional glutamatergic transmission in the early days of embryonic cultures. In support of this conclusion, overexpression of AMPA receptors in immature neurons has been shown to significantly increase the frequency of spontaneous EPSCs (Fig. 8). Therefore, the low expression level of glutamate receptors in embryonic neurons may result in a slow postsynaptic differentiation, which can be a bottleneck for glutamatergic synapse formation as suggested by previous studies (Fletcher et al., 1994; Ahmari et al., 2000; Friedman et al., 2000).

A sequential formation of GABAergic synapses followed by glutamatergic synapses has been originally reported during embryonic and early postnatal development of the hippocampus (Tyzio et al., 1999; Khazipov et al., 2001; Hennou et al., 2002). However, the molecular mechanism underlying such sequential synaptogenesis is not known. Based on our current study of both GABAergic and glutamatergic synaptogenesis, we propose that a difference in the postsynaptic development, especially the expression level of $\mathrm{GABA}_{\mathrm{A}}$ versus glutamate receptors, may be a critical element in governing the sequential synapse assembly.

Synaptogenesis has often been reported at two different timescales, ranging from a few hours to several days after axodendritic contact (van den Pol et al., 1998; Ahmari et al., 2000; Friedman et al., 2000; Washbourne et al., 2002). Both timescales were observed in the present study of GABAergic synaptogenesis. We showed that IPSCs can be rapidly detected in cocultured immature neurons within 4-6 h of contact with mature neurons, but in pure young cultures it generally takes several days for the majority of neurons to show IPSCs. The slow timescale of several days of synaptogenesis in pure young cultures reflects the time required for initial gene expression for receptors and synaptic proteins, neurite extension, axodendritic contact, and subsequent presynaptic and postsynaptic differentiation. In contrast, neurons that have already been cultured for several days start to possess prefabricated packets in both presynaptic and postsynaptic compartments, which may be independently functional before meeting with each other (Ahmari et al., 2000; Friedman et al., 2000; Washbourne et al., 2002; Krueger et al., 2003). Therefore, the fast timescale of several hours of synaptogenesis reported previously may represent a rapid alignment of already functional presynaptic and postsynaptic counterparts into one integrated synapse. However, in our coculture system, the immature neurons were newly dissociated from embryos (E15-E16), and the presynaptic and postsynaptic development in these dissociated neurons are truly de novo. Considering the newly dissociated neurons that are plated together with mature neurons are essentially round balls without any neurites, the rapid appearance of spontaneous IPSCs within $4-6 \mathrm{~h}$ of contact with mature neurons suggest that the formation of a functional GABAergic postsynaptic apparatus is almost instantaneous. The implication of this extremely fast GABAergic synaptogenesis is very important: first, 
it suggests that the embryonic neurons must have cell adhesion molecules expressed on the somadendritic membranes to mediate the initial axon-dendritic contacts. Second, the postsynaptic assembly of GABAergic synapses must use a simple mechanism to rapidly cluster the $\mathrm{GABA}_{\mathrm{A}}$ receptors under presynaptic terminals. We have recently expressed a cell adhesion molecule neuroligin-2 and $\mathrm{GABA}_{\mathrm{A}}$ receptors in HEK293T cells and cocultured them with hypothalamic neurons. Robust spontaneous as well as evoked GABAergic events were readily recorded in transfected HEK293T cells, suggesting that neuroligin-2 and $\mathrm{GABA}_{\mathrm{A}}$ receptors may be sufficient to form functional GABAergic postsynaptic apparatus (Dong et al., 2007).

In conclusion, we demonstrate here that functional assembly of GABAergic synapses differs significantly from that of glutamatergic synapses. Such difference in the establishment of GABAergic versus glutamatergic synapses during embryonic development may be critical in constructing brain circuits in a right order. Our findings underscore the complexity of synapse formation in the CNS and different types of central synapses may be functionally constructed through distinct mechanisms.

\section{References}

Ahmari SE, Buchanan J, Smith SJ (2000) Assembly of presynaptic active zones from cytoplasmic transport packets. Nat Neurosci 3:445-451.

Alldred MJ, Mulder-Rosi J, Lingenfelter SE, Chen G, Luscher B (2005) Distinct $\gamma 2$ subunit domains mediate clustering and synaptic function of postsynaptic $\mathrm{GABA}_{\mathrm{A}}$ receptors and gephyrin. J Neurosci 25:594-603.

Baer K, Essrich C, Balsiger S, Wick MJ, Harris RA, Fritschy JM, Luscher B (2000) Rescue of gamma2 subunit-deficient mice by transgenic overexpression of the GABAA receptor gamma2S or gamma2L subunit isoforms. Eur J Neurosci 12:2639-2643.

Benson DL, Watkins FH, Steward O, Banker G (1994) Characterization of GABAergic neurons in hippocampal cell cultures. J Neurocytol 23:279-295.

Betz WJ, Bewick GS (1992) Optical analysis of synaptic vesicle recycling at the frog neuromuscular junction. Science 255:200-203.

Brunig I, Suter A, Knuesel I, Luscher B, Fritschy JM (2002) GABAergic terminals are required for postsynaptic clustering of dystrophin but not of $\mathrm{GABA}_{\mathrm{A}}$ receptors and gephyrin. J Neurosci 22:4805-4813.

Chen G, Trombley PQ, van den Pol AN (1996) Excitatory actions of GABA in developing rat hypothalamic neurones. J Physiol (Lond) 494:451-464.

Chen Y, Deng LB, Maeno-Hikichi Y, Lai MZ, Chang SH, Chen G, Zhang JF (2003) Formation of an endophilin- $\mathrm{Ca}^{2+}$ channel complex is critical for clathrin-mediated synaptic vesicle endocytosis. Cell 115:37-48.

Christie SB, Miralles CP, De Blas AL (2002a) GABAergic innervation organizes synaptic and extrasynaptic $\mathrm{GABA}_{\mathrm{A}}$ receptor clustering in cultured hippocampal neurons. J Neurosci 22:684-697.

Christie SB, Li RW, Miralles CP, Riquelme R, Yang BY, Charych E, Wendou Y, Daniels SB, Cantino ME, De Blas AL (2002b) Synaptic and extrasynaptic GABAA receptor and gephyrin clusters. Prog Brain Res 136:157-180.

Danglot L, Triller A, Bessis A (2003) Association of gephyrin with synaptic and extrasynaptic GABAA receptors varies during development in cultured hippocampal neurons. Mol Cell Neurosci 23:264-278.

Decavel C, Van den Pol AN (1990) GABA: a dominant neurotransmitter in the hypothalamus. J Comp Neurol 302:1019-1037.

Deng LB, Chen G (2003) Cyclothiazide potently inhibits $\gamma$-aminobutyric acid type A receptors in addition to enhancing glutamate responses. Proc Natl Acad Sci USA 100:13025-13029.

Dong N, Qi J, Chen G (2007) Molecular reconstitution of functional GABAergic synapses with expression of neuroligin-2 and GABAA receptors. Mol Cell Neurosci 35:14-23.

Dumoulin A, Levi S, Riveau B, Gasnier B, Triller A (2000) Formation of mixed glycine and GABAergic synapses in cultured spinal cord neurons. Eur J Neurosci 12:3883-3892.
Ehlers MD (2000) Reinsertion or degradation of AMPA receptors determined by activity-dependent endocytic sorting. Neuron 28:511-525.

Essrich C, Lorez M, Benson JA, Fritschy JM, Luscher B (1998) Postsynaptic clustering of major GABAA receptor subtypes requires the gamma 2 subunit and gephyrin. Nat Neurosci 1:563-571.

Fletcher TL, De Camilli P, Banker G (1994) Synaptogenesis in hippocampal cultures: evidence indicating that axons and dendrites become competent to form synapses at different stages of neuronal development. J Neurosci 14:6695-6706.

Friedman HV, Bresler T, Garner CC, Ziv NE (2000) Assembly of new individual excitatory synapses: time course and temporal order of synaptic molecule recruitment. Neuron 27:57-69.

Fritschy JM, Mohler H (1995) GABAA-receptor heterogeneity in the adult rat brain: differential regional and cellular distribution of seven major subunits. J Comp Neurol 359:154-194.

Hennou S, Khalilov I, Diabira D, Ben-Ari Y, Gozlan H (2002) Early sequential formation of functional GABAA and glutamatergic synapses on CA1 interneurons of the rat foetal hippocampus. Eur J Neurosci 16:197-208.

Jiang M, Chen G (2006) High $\mathrm{Ca}^{2+}$-phosphate transfection efficiency in low-density neuronal cultures. Nat Protoc 1:695-700.

Khazipov R, Esclapez M, Caillard O, Bernard C, Khalilov I, Tyzio R, Hirsch J, Dzhala V, Berger B, Ben-Ari Y (2001) Early development of neuronal activity in the primate hippocampus in utero. J Neurosci 21:9770-9781.

Krueger SR, Kolar A, Fitzsimonds RM (2003) The presynaptic release apparatus is functional in the absence of dendritic contact and highly mobile within isolated axons. Neuron 40:945-957.

Li RW, Yu W, Christie S, Miralles CP, Bai J, Loturco JJ, De Blas AL (2005) Disruption of postsynaptic GABA receptor clusters leads to decreased GABAergic innervation of pyramidal neurons. J Neurochem 95:756-770.

Luscher B, Keller CA (2004) Regulation of GABAA receptor trafficking, channel activity, and functional plasticity of inhibitory synapses. Pharmacol Ther 102:194-220.

Moss SJ, Smart TG (2001) Constructing inhibitory synapses. Nat Rev Neurosci 2:240-250.

Paramore CG, Turner DA, Madison RD (1992) Fluorescent labeling of dissociated fetal cells for tissue culture. J Neurosci Methods 44:7-17.

Ryan TA, Reuter H, Wendland B, Schweizer FE, Tsien RW, Smith SJ (1993) The kinetics of synaptic vesicle recycling measured at single presynaptic boutons. Neuron 11:713-724.

Schweizer C, Balsiger S, Bluethmann H, Mansuy IM, Fritschy JM, Mohler H, Luscher B (2003) The gamma 2 subunit of $\mathrm{GABA}_{\mathrm{A}}$ receptors is required for maintenance of receptors at mature synapses. Mol Cell Neurosci 24:442-450.

Studler B, Sidler C, Fritschy JM (2005) Differential regulation of GABA receptor and gephyrin postsynaptic clustering in immature hippocampal neuronal cultures. J Comp Neurol 484:344-355.

Tyzio R, Represa A, Jorquera I, Ben-Ari Y, Gozlan H, Aniksztejn L (1999) The establishment of GABAergic and glutamatergic synapses on CA1 pyramidal neurons is sequential and correlates with the development of the apical dendrite. J Neurosci 19:10372-10382.

van den Pol AN, Trombley PQ (1993) Glutamate neurons in hypothalamus regulate excitatory transmission. J Neurosci 13:2829-2836.

van den Pol AN, Obrietan K, Belousov AB, Yang Y, Heller HC (1998) Early synaptogenesis in vitro: role of axon target distance. J Comp Neurol 399:541-560.

Waites CL, Craig AM, Garner CC (2005) Mechanisms of vertebrate synaptogenesis. Annu Rev Neurosci 28:251-274.

Washbourne P, Bennett JE, McAllister AK (2002) Rapid recruitment of NMDA receptor transport packets to nascent synapses. Nat Neurosci 5:751-759.

Yao J, Qi J, Chen G (2006) Actin-dependent activation of presynaptic silent synapses contributes to long-term synaptic plasticity in developing hippocampal neurons. J Neurosci 26:8137-8147.

Ziv NE, Garner CC (2004) Cellular and molecular mechanisms of presynaptic assembly. Nat Rev Neurosci 5:385-399.

Zucker RS, Regehr WG (2002) Short-term synaptic plasticity. Annu Rev Physiol 64:355-405. 